Nuntius Antiquus, Belo Horizonte, v. 12, n. 1, p. 117-130, 2016

\title{
Hic ego dux milesque bonus: As Armas de Eros na Elegia Romana
}

\author{
Hic ego dux milesque bonus: The Eros' Weapons \\ in the Roman Elegy
}

\begin{abstract}
Alexandre Agnolon
Universidade Federal de Ouro Preto

Ouro Preto, MG - Brasil

agnolon@gmail.com
\end{abstract}

Resumo: O presente artigo tem como objetivo principal discutir a representação de Eros na elegia romana a partir de exemplos tomados de poetas como Tibulo, Propércio e Ovídio. Buscar-se-á demonstrar que a imago do deus entre os poetas elegíacos romanos serve tanto para figurar, alegoricamente, a própria poesia elegíaca e o sofrimento amoroso, pois que o deus figura a militia amoris e a seruitium amoris, como para representar o éthos da persona loquens elegíaca. Nesse sentido, Eros, bem como a incorporação, em dimensão poética, de imagens de natureza bélica, é expediente programático, já que mediante estratégia visualizante os poetas elegíacos figuravam princípios retórico-poéticos do gênero.

Palavras-Chave: Eros; elegia; poética; retórica; sofrimento amoroso.

Abstract: This paper aims to discuss the representation of Eros in the Roman elegy from examples taken from poets such as Tibullus, Propertius and Ovid. We seek to demonstrate that the imago of the god among the Roman elegiac poets serves not only to figure, allegorically, the very elegiac poetry and the love suffering itself - because the god figures the militia amoris and the seruitium amoris as well - but also to represent the ethos of the elegy's persona loquens. In this sense, Eros, and the incorporation in poetic dimension of military content images, is a 
118 Nuntius Antiquus, Belo Horizonte, v. 12, n. 1, p. 117-130, 2016

programmatic expedient, since the elegiac poets figured rhetorical-poetic principles of the genre by means of visual strategies.

Keywords: Eros; elegy; poetics; rhetoric; love suffering.

Artigo recebido em 10 de outubro de 2015 Aprovado para publicação em 12 de novembro de 2015

O título deste breve ensaio possui um certo caráter difuso, pois tomo a Tibulo a passagem latina do título - trata-se do verso 75 da primeira elegia do livro I ("aqui sou general e bom soldado") -; no entanto, enquanto escrevia, não nego que pensava em Ovídio, que, como se sabe, explorou não só todas as possibilidades de composição da elegia, pelo menos quanto à feição que o gênero tomou entre os romanos, mas sobretudo foi o poeta que levou às últimas consequências a figuração do próprio Eros, a ponto de, em certo sentido, o deus julgar que o poeta, o seu poeta, declarara-lhe guerra. ${ }^{1}$ Meu objetivo, portanto, é tratar da figuração de Eros/Cupido, mais precisamente como as características associadas ao éthos do deus relacionam-se com o gênero elegíaco, em particular com o moto próprio da persona loquens. Parece-me que, a despeito da ironia imanente da elegia romana, é justamente Eros quem toma de assalto esse gênero de poesia, contribuindo, pois, para o grau de sofisticação da elegia erótica romana que, como sabemos, foi fundamental para a poesia do Ocidente, ${ }^{2}$ bem como para as representações

${ }^{1}$ Cf. Ovídio, Remedia Amoris, 1-4: "O Amor tinha lido o título e o nome deste livrinho: 'são guerras - estou vendo - são guerras que se preparam contra mim', disse ele. Abstém-te, Cupido, de condenar por crime o teu poeta, eu que tantas vezes portei, sob teu comando, a bandeira que me confiaste", Legerat huius Amor titulum nomenque libelli:/ 'Bella mihi, uideo, bella parantur' ait./'Parce tuum uatem sceleris damnare, Cupido,/ Tradita qui toties te duce signa tuli. Tradução de Antônio da Silveira Mendonça.

${ }^{2}$ Cf. Veyne (1985, p. 9): “Até aqui podemos acreditar que estamos em terras conhecidas; pensamos em Dante ou em Petrarca contando seus amores platônicos por Beatriz e Laura, nos trovadores cantando uma dama nobre sob um pseudônimo ou senhal, em Scève com sua Délia, em Ronsard com sua Cassandra. E é bem verdade que, no Ocidente, a elegia romana teve uma posteridade que, legítima ou não, durará até Lamartine ou Aragon". Cf. também Grimal (1991); Lapa (1929, p. 85): "Os trovadores, por conseguinte, pertencem bem à tradição escolar médio-latina, porque utilizam essencialmente o seu processo retórico. Não se creia, porém, que a influência clássica passada pelo crivo 
amorosas no discurso poético de um modo geral, inclusive na pintura. ${ }^{3}$ Comecemos pela imagem do deus menino: Propércio foi o primeiro a tratar, em discurso elegíaco, de sua imago. O poeta lê a representação de Eros iconologicamente: a descrição, alegórica, catalisa poderosamente no menino o amor feroz e, ao mesmo tempo, cativante, capaz de a todos submeter. Ora, vejam o quanto é difusa minha fala, pois acabo por começar não por Tibulo, nem por Ovídio, mas por Propércio:

Quicumque ille fuit, puerum qui pinxit Amorem, nonne putas miras hunc habuisse manus?

is primum uidit sine sensu uiuere amantes, et leuibus curis magna perire bona.

idem non frustra uentosas addidit alas, fecit et humano corde uolare deum:

scilicet alterna quoniam iactamur in unda, nostraque non ullis permanet aura locis.

et merito hamatis manus est armata sagittis, et pharetra ex umero Cnosia utroque iacet:

ante ferit quoniam tuti quam cernimus hostem, nec quisquam ex illo uulnere sanus abit.

in me tela manent, manet et puerilis imago: sed certe pennas perdidit ille suas;

euolat heu nostro quoniam de pectore nusquam, assiduusque meo sanguine bella gerit.

quid tibi iucundumst siccis habitare medullis? si pudor est, alio traice tela, puer!

intactos isto satius temptare ueneno:

non ego, sed tenuis uapulat umbra mea.

quam si perdideris, quis erit qui talia cantet, (haec mea Musa leuis gloria magna tuast), qui caput et digitos et lumina nigra puellae et canat ut soleant molliter ire pedes?

medieval se limitou apenas a Ovídio. Vossler fazia já aproximações entre Bernardo e Catulo, Propércio e Tibulo, opinando até que a arte fina e alada do grande trovador tem o quer que seja de helênico que o aproxima ainda mais destes últimos do que de Ovídio". O mesmo Rodrigues Lapa (1929, p. 20) menciona rapidamente, só para atestar a centralidade dos elegíacos para a composição "lírica" do medievo, que os goliardos a Ovídio chamavam "Papa Nasão".

${ }^{3}$ É muito elucidativo nesse sentido o ensaio de Carlo Ginzburg (2009, p. 119-141), "Ticiano, Ovídio e os códigos de figuração erótica no século XVI". 
Quem quer que seja que pintou o Amor menino, não julgas que este tinha mãos sublimes?

Viu primeiro os amantes viver sem juízo e por tolices perecer fortunas.

Asas ventosas não juntou em vão e fez

voar o deus no humano coração:

porque decerto às vagas nos lança alternadas, e a brisa nossa em parte alguma jaz.

É justo que nas mãos leve frechas aduncas

e de Cnossos aljava penda do ombro:

ele nos fere antes de vermos o inimigo,

daquela chaga são ninguém escapa.

Jazem em mim as setas e a pueril imagem,

contudo - é certo! - perdeu ele as asas

porque, ai, do meu peito ele não se evade nunca

e, assíduo, guerras move com meu sangue!

Por que habitar te agrada um coração exausto?

Lança em outro, menino, as tuas setas!

O veneno - é melhor! - destila em gente sã!

Não eu! Mas minha tênue sombra açoitas!

Se a perderes, amores quem cantará? (Minha

Musa suave é tua grande glória)

Quem, a cabeça, os dedos e os negros olhinhos

da menina, ou o meigo andar dos pés?

(PROPÉRCIO. Elegias, II, 12, tradução nossa)

A ékphrasis de Cupido elaborada por Propércio emula muito provavelmente um exercício retórico. Quintiliano faz referência a algo bastante parecido no segundo livro das Instituições Oratórias. Segundo o rétor latino, era prática comum dos preceptores exortar os alunos a desenvolver questões do tipo: "entre os lacedemônios, por que Vênus é representada armada" ou, o que é exatamente o ponto da elegia de Propércio, "Por que assim se crê que seja Cupido menino e alado, bem como provido de flechas e tocha?". Para Quintiliano, incentivar os jovens a essa espécie de exercício, ou seja, "sondar a natureza do desejo", correspondia, retórica e pragmaticamente, a prepará-los para as "causas conjecturais" (QUINTILIANO. Instituições Oratórias, II, 4, 26), essenciais para as narrações dos proêmios dos discursos, uma vez que mediante sinais e outras observações de ordem visualizante o orador não só seria capaz de gerar afecções na audiência, mas sobretudo expor, 
indutivamente, certas pistas aos olhos dos ouvintes, "sinais" estes, signa, que sustentariam, mediante a subsequente apresentação das provas, as motivações de um crime, por exemplo. ${ }^{4} \mathrm{Na}$ Retórica a Herênio, o Anônimo ensina que na narração o acusador deve, de tal maneira lançar suspeitas pelo caminho, que pareça ser tudo "motivado", sine causa putetur. Nesse sentido, a narratio de Propércio faz o mesmo, a leitura digamos "iconológica" (PANOFSKY, 2007) do poeta - endossemos o anacronismo - faz sobredeterminar o significante, o efeito faz parecer com que Eros/Cupido, nos índices de sua figuração, torne-se natural, justamente pela naturalização de suas características físicas que, significantes, correspondem, pois, aos atributos que se lhe associam no campo do desejo. O procedimento, escancara-o a preceptiva retórica, põe em cena, sem dúvida, o artifício, de modo que, se de um lado é inaudito, descrição tão bem-acabada de Cupido na elegia entre os romanos, de outro, a estratégia discursiva do poeta demonstra o uso tópico da imago de Eros e o uso tópico do amor na elegia e os padecimentos por que passa, na ficção do poema, a persona loquens.

Ora, os dísticos finais o demonstram: não há elegia sem padecimentos, não há elegia sem servidão amorosa, quer à vontade de Eros, quer à vontade da puella. Os padecimentos e a servidão, bem entendidos, são tópicos fundamentais da elegia: é justamente o açoitar da sombra do poeta o detonador do discurso amoroso. Ora, o amor de Eros, no poema - e talvez em toda a elegia romana -, é phármakon, veneno-remédio, que, na fictio do gênero, se é verdade pode pôr a perder o poeta, não é menos verdadeiro que põe sem dúvida a ganhar a poesia. Nesse caso, poderíamos propor a Propércio exatamente o argumento inverso, em certo sentido, índice aí do dispositivo irônico que é a elegia romana: certamente, a morte cala a voz do poeta - ou, ao contrário, torna-a imortal -, mas, por outro lado, sem a paixão, a verdadeira mania inspirada por Eros, não há elegia: aí reside o jogo irônico da fala elegíaca

\footnotetext{
${ }^{4} \mathrm{Na}$ Retórica a Herênio (II, 3), assim define o Anônimo o que seja "causa conjectural": "Na causa conjectural, a narração do acusador deve lançar suspeitas aqui e ali, de modo que todo ato, todo dito, todas as idas e vindas, tudo, enfim, pareça motivado. A narração do defensor deve ter exposição simples e clara, com atenuação da suspeita", In causa coniecturali narratio accusatoris suspiciones interiectas et dispersas habere debet, ut nihil actum, nihil dictum, nusquam uentum aut abitum, nihil denique factum sine causa putetur. Defensoris narratio simplicem et dilucidam expositionem debet habere cum adtenuatione suspicionis. Tradução de Ana Paula Celestino Faria e Adriana Seabra.
} 
122 Nuntius Antiquus, Belo Horizonte, v. 12, n. 1, p. 117-130, 2016

que, invertendo os papeis, passa a chantagear o deus: "minha sombra [...] se a perderes, quem amores cantará?" Estando o poeta livre dos desígnios do deus, quem, acaso, cantará os amores? Quem cantará a menina, a fronte, seus negros olhos e seus pés molemente caminhando? (referência, porventura, à estrofe elegíaca?). Há um epigrama de Marcial - em dísticos elegíacos, aliás - que bem ilustra o argumento, pois talvez seja indicador de que os sofrimentos gerados pelo Amor correspondem, em elegia, a ingrediente fundamental:

\author{
Monobyblos Properti \\ Cynthia - facundi carmen iuuenale Properti - \\ accepit famam, non minus ipsa dedit. \\ O Monobyblos de Propércio \\ Cíntia - o jovem libelo do agudo Propércio! - \\ ganhou fama: não menos fez por ele.
}

(MARCIAL, Apoforeta, XIV, 189, tradução nossa)

Cíntia - a amada do Propércio e ao mesmo tempo referência provável ao título original de seu livro de elegias ${ }^{5}$ - ganhou a fama devida, mas o poeta também. É como se os sofrimentos e contrariedades a que o poeta fora submetido por Cíntia fossem o preço da fama imortal de suas elegias: o livro ganhou fama, é verdade - e Cíntia, a amada, paradigmática, porque metáfora poderosa da puella elegíaca -, mas também, como que em paga pelos padecimentos que impôs, conferiu a Propércio imortalidade, a palma desejada por todos os poetas, já nos ensinara Horácio (Odes, III, 30). É engenhoso o epigrama, contudo, Marcial, conhecedor de poesia, êmulo inclusive dos elegíacos da época de Augusto, traduz também a presença tópica de Eros na elegia romana, como se entrevê. Por falar em Cíntia, não há como se esquecer da primeira elegia do livro I de Propércio, que se inicia precisamente com Cíntia - nome da amada, nome do livrinho. Recordemos os primeiros versos:

\footnotetext{
${ }^{5}$ Cf. Martins (2009, p. 35): “[...] Pode-se, também, dizer que há um outro ponto de contato entre o poeta de Côlofon e o da Úmbria [a saber: Propércio], aquele nomeia seu livro de elegias 'Nanno', como gostam os biografistas: sua 'amada'. Ter-se-ia, assim, um análogo distante temporariamente e próximo semanticamente: o livro de 'Cíntia”".
} 
Cynthia prima suis miserum me cepit ocellis, contactum nullis ante cupidinibus.

tum mihi constantis deiecit lumina fastus et caput impositis pressit Amor pedibus, donec me docuit castas odisse puellas improbus, et nullo uiuere consilio.

Cíntia, a primeira, me prendeu com seus olhinhos

Um coitado intocado por desejos;

Então Amor tirou-me a altivez do olhar

E me oprimiu a testa com seus pés,

Até que me ensinou, malvado, a odiar

Moça casta e a viver em desatino.

(PROPÉRCIO. Elegias, I, 1, 1-6, tradução de Guilherme Gontijo Flores)

Não há apresentação das circunstâncias do encontro entre o poeta e Cíntia, o ritmo é feroz. Simplesmente o Amor toma o poeta de assalto, atinge-o em cheio; como na passagem de Propércio apresentada antes, não há tempo de o poeta vislumbrar o inimigo. É evidente, na elegia, as setas do menino figuradas nos olhinhos de Cíntia, pequenos porque delicados, sim, mas sobretudo o diminutivo é indicativo de que são penetrantes, pungentes como as flechas que Cupido carrega à aljava; além disso, talvez seja possível supor que a referida pungência dos olhos seja indício também da agudeza intelectual da menina, cumprindo, pois, o topos da docta puella elegíaca (PROPÉRCIO. Elegias, I, 7, 11: II, 13, 11), comum posteriormente em Ovídio e, em certo sentido, antes em Catulo. Seja como for, cumpre notar o principal: as "frechadas" de Cíntia atingem o poeta e o prendem, finalmente, sob o jugo de Eros. Este, por sua vez, pressiona com os pés a cabeça do poeta ao chão, antes arrogante, de olhar altivo, intocado pelo Amor. Agora jaz ao chão, submisso à vontade do deus, remetendo, assim, a imagens do campo bélico, incorporadas à poesia.

Nesse sentido, se levado em consideração o contexto de consolidação do regime de Augusto, poderíamos supor a presença de referência indireta às circunstâncias de expansão do império, mediante o poder militar do princeps - não é necessário dizer que em não poucas elegias as vitórias de Otávio são aludidas, exemplos importantes são as campanhas de Messala diretamente mencionadas por Tibulo; o poeta, a propósito, delas participara como lugar-tenente. Nas elegias programáticas de Ovídio, o poder de Eros sobre a persona loquens também se evidencia, 
124 Nuntius Antiquus, Belo Horizonte, v. 12, n. 1, p. 117-130, 2016

estabelecendo, de um lado, os critérios de verossimilhança que, por seu turno, construíam o cenário elegíaco, de outro, como vimos em Propércio, eram responsáveis de certo modo por forjar o éthos do poeta elegíaco, o que implica no queixume próprio do lamento amoroso. Vejamos a elegia primeira do livro I dos Amores:

Arma graui numero uiolentaque bella parabam edere, materia conueniente modis.

par erat inferior uersus - risisse Cupido dicitur atque unum surripuisse pedem.

'Quis tibi, saeue puer, dedit hoc in carmina iuris?

Pieridum vates, non tua turba sumus.

quid, si praeripiat flauae Venus arma Mineruae, uentilet accensas flaua Minerua faces?

quis probet in silvis Cererem regnare iugosis, lege pharetratae Virginis arua coli?

crinibus insignem quis acuta cuspide Phoebum instruat, Aoniam Marte mouente lyram? sunt tibi magna, puer, nimiumque potentia regna; cur opus adfectas, ambitiose, nouum? an, quod ubique, tuum est? tua sunt Heliconia tempe? uix etiam Phoebo iam lyra tuta sua est? cum bene surrexit uersu noua pagina primo, attenuat neruos proximus ille meos; nec mihi materia est numeris leuioribus apta, aut puer aut longas compta puella comas.'

Questus eram, pharetra cum protinus ille soluta legit in exitium spicula facta meum, lunauitque genu sinuosum fortiter arcum, 'quod' que 'canas, uates, accipe' dixit 'opus!'

Me miserum! certas habuit puer ille sagittas. uror, et in vacuo pectore regnat Amor.

Sex mihi surgat opus numeris, in quinque residat:

ferrea cum uestris bella ualete modis! cingere litorea flauentia tempora myrto, Musa, per undenos emodulanda pedes!

Preparava-me para armas e violentas guerras em ritmo grave Cantar, sendo a matéria conveniente ao metro. $\mathrm{O}$ segundo verso era igual ao primeiro. Cupido riu Conta-se - e roubou um pé. 
"cruel menino, quem te deu em poesia este direito?

Eu, poeta inspirado pelas Piérides, não sou da tua turma!

O que será se Vênus roubar armas da loura Minerva

E se a loura Minerva agitar no ar tochas acesas?

Quem aprovaria que Ceres reinasse sobre selvas montanhosas

E que os campos fossem cultivados sob a lei da virgem que porta a aljava?

Febo, notável pelos cabelos, quem da lança aguda

O proveria, enquanto Marte tocasse a lira aônia?

Grandes e poderosos, menino, são teus reinos;

Por que, ambicioso, buscas um novo gênero?

Ou será que tudo, por toda parte, é teu? São teus os vales de Tempe?

Até mesmo Febo protege a própria lira com dificuldade?

Toda vez que uma nova página começa com um primeiro verso,

O seguinte vem atenuar meu vigor.

E não tenho matéria apta a um ritmo mais leve,

Um menino, ou menina de cabelos longos, penteados."

Assim me queixara, quando Cupido, abrindo incontinente a aljava, Apanhou flechas destinadas à minha perdição,

Curvou com força o sinuoso arco no joelho

E disse: "toma aqui, poeta inspirado, um gênero para cantares."

Ai de mim!, o menino tinha certeiras setas!

Ardo e em meu peito, que era livre, reina Amor.

Que minha obra comece com seis pés e se detenha em cinco!

Adeus, guerras cruéis e seus ritmos próprios!

Coroa-me, Musa, as louras têmporas com mirto ribeirinho,

Tu que deves ser modulada com onze pés.

(OVÍDIO Amores, I, 1, tradução de João Angelo Oliva Neto)

A elegia de Ovídio apresenta o princípio de decoro da poesia elegíaca, atrelando o metro à matéria erótico-amorosa. A recusa aos gêneros elevados, explicitada no início do poema, atrela-se à peça que Cupido prega no poeta, roubando-lhe um pé: transformando, pois, o ritmo páreo do hexâmetro datílico na estrofe elegíaca; segue-se ao hexâmetro, outro hexâmetro, mas cataléptico, ou seja, coxo por obra de Cupido. A brincadeira da divindade rompe o princípio de decoro proposto por Ovídio no início, colocando em frangalhos os intentos heróicos do poeta. Pronto para cantar as armas, as violentas guerras no andamento próprio, conveniente da epopeia, Ovídio se vê agora, por obra de Cupido, perdido, sem matéria apta para os onze pés de que dispõe. Curioso na elegia que o mesmo Eros, responsável pelo caos que institui, é o mesmo que põe fim 
ao dilema de Ovídio: não lhe devolve o pé, é verdade. Mas o atinge com suas armas. As flechas certeiras, que fazem agora arder o peito do poeta, tornando-lhe cativo dos desígnios de Eros, são as mesmas que tornam o éthos do poeta, na ficção do poema, apto a cantar elegia. Há, na elegia de Ovídio, a explicitação de um princípio compositivo muito semelhante ao que se viu nos versos de Propércio: em Roma, tornar-se presa de Eros é mister para qualquer poeta que ambicione compor opus elegíaco. $\mathrm{O}$ preço da palma é a submissão ao Amor. O sucesso vem, paradoxalmente, com o cativeiro. Nesse sentido, entregar-se a Eros, ser atingido por suas flechas se converte em espécie de rito iniciático, é necessário fazer parte dos mistérios do deus. Ostentar suas flechas equivale, em poesia, a ser vaticinado poeta elegíaco: a cena não remeteria a Hesíodo? ${ }^{6}$

Capitular às armas de Eros significa ainda carregar os estandartes do deus. O poeta elegíaco nunca é apenas derrotado, pois passa para as fileiras de Eros. O poeta elegíaco é sempre misto de cativo e soldado. Portanto, seus sofrimentos, seus padecimentos, a derrota, o queixume implicam também em outro tópos fundamental da elegia: a milita amoris. O motivo aparece recorrentemente em Ovídio e em Propércio, como se sabe, mas antes deles Tibulo já havia versado a temática. Vejamos a última parte da primeira elegia de Tibulo:

\footnotetext{
Interea, dum fata sinunt, iungamus amores:

Iam ueniet tenebris Mors adoperta caput,

Iam subrepet iners aetas, nec amare decebit,

Dicere nec cano blanditias capite.

Nunc leuis est tractanda Venus, dum frangere postes

Non pudet et rixas inseruisse iuuat.

Hic ego dux milesque bonus: uos, signa tubaeque,

Ite procul, cupidis uolnera ferte uiris,

Ferte et opes: ego conposito securus aceruo

Despiciam dites despiciamque famem.
}

\footnotetext{
${ }^{6}$ É possível imaginar, mais ainda se pensarmos no teor profundamente irônico do discurso elegíaco, que ostentar no peito as armas de Eros, quase como insígnias, remeta parodicamente à cena, na Teogonia (vv. 22-34), do vaticínio de Hesíodo, quando as Musas lhe conferem o ramo de loureiro, distinguindo-o, assim, poeta. Para o caráter irônico da figuração dos poetas elegíacos, recomendamos o excelente estudo de Allen (1950, p. 145-160).
} 
Enquanto anui o fado, ponhamos amores sob mesmo jugo;

logo virá a Morte com a cabeça cingida de trevas, logo a idade se insinuará tímida, aí não convirá mais amar, nem dizer blandícias com a cabeça alva.

Agora é que deve ser satisfeita a ligeira Vênus, enquanto não é vergonha quebrar umbrais e agrada ainda meter-se em rixas.

Aqui sou bom general e soldado: vós, trombetas e estandartes, 75 ide embora para longe! Aos varões ávidos ferimentos levai!

Levai também riquezas! Eu, seguro com moderada soma, desprezarei os abastados e desprezarei a fome.

(TIBULO, I, 1, 69-78, tradução nossa)

Se é verdade que a força das armas de Eros foi motivo recorrente entre os poetas elegíacos augustanos, já que, como vimos, fora responsável por figurar não só a natureza contraditória do sentimento amoroso, mas sobretudo o caráter do eu-elegíaco - na poesia, princípio de decoro -, é verdade também que o tema já era helenístico, epigramático em particular e já incorporado ao dístico elegíaco, como nos parece demonstrar o seguinte epigrama de Asclepíades de Samos (ca 350 a.C.), conservado na Antologia Palatina:

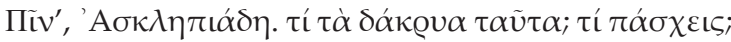

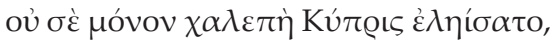

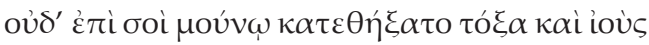

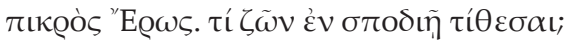

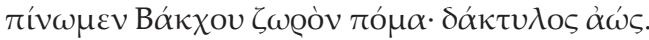

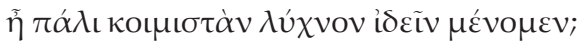

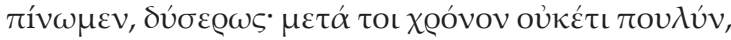

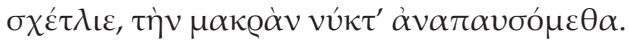

Asclepíades, bebe! Por que estás em prantos?

Não venceu-te a ti só a dura Cípris.

Só contra ti lançou flechas Eros pungente?

Estás vivo! Sucumbes por que às cinzas?

Bebamos dons de Baco! Já desponta a Aurora!

A Candeia, de novo, vamos ver?

Bebamos, infeliz! O tempo urge, pois logo,

Mísero, a longa noite dormiremos.?

\footnotetext{
${ }^{7}$ Antologia Palatina, XII, 50. Tradução nossa. Repare-se que o último verso do poema 5 de Catulo - o verso 6: nox est perpetua una dormienda - é muito provavelmente reelaboração do desfecho do epigrama de Asclepíades.
} 
Seja como for, entre os gregos, Eros e Afrodite, impossível não dizê-lo, constituíram-se potências importantes. A manía inspirada pelo Deus no Fedro de Platão, por exemplo, não é só paixão "amorosa", é princípio de conhecimento, medium de ascese ao mundo das ideias. No discurso trágico, o fado de Hipólito é determinado por Afrodite, que inspira Fedra de amores pelo enteado: rejeitada, a loucura suicida lhe inspira a carta, cujo falso testemunho sela o destino de Hipólito. O mais fraco é arrastado pelo mais forte. Que força tem o homem para resistir às deidades? Górgias, antes ainda, absolvera Helena dos seus desatinos: seja levada à força por Páris, seja persuadida pelos discursos, é sobretudo o poder de Eros que lhe destitui as forças, que lhe põe a perder nos braços de Páris e, com isso, Troia inteira. No entanto, o indício, ainda na Antiguidade, da importância e longevidade da elegia romana - a grande imagem da força e das armas de Eros - seja a Eneida. Poeta poderoso, Virgílio canta a fundação das bases de Roma, a nova Troia a subjugar o mundo, corolário de Augusto, mas canta também os amores de Dido e Eneias. Amor avassalador, inspirado por Eros-Ascânio que, no colo da rainha, dispara as flechas destinadas para sua perdição. Antecede ao suicídio da rainha de Cartago, a preferida de Juno, o verdadeiro canto elegíaco do amor-perdição de Dido. Tal a força das armas de Eros, tal a força da elegia romana, que até a sublimidade épica se curva diante de Eros: até Virgílio compõe elegia.

\section{Referências}

ALLEN, A. Sincerity and the Roman Elegists. Classical Philology, Chicago, v. 45, n. 3, p. 145-160, 1950.

CATULLUS, TIBULLUS, PERUIGILIUM VENERIS. The poems of Gaius Valerius Catullus. Translated by F.W. Cornish; Tibullus, by J.P. Postgate; and Pervigilium Veneris, by J.W. Mackail. Cambridge, Mass.; London: Harvard University Press: W. Heinemann, 1995.

CATULO. O livro de Catulo. Tradução, introdução e notas de J. A. Oliva Neto, São Paulo: EDUSP, 1996.

[CÍCERO]. Retórica a Herênio. Tradução e introdução Ana Paula Celestino Faria e Adriana Seabra. São Paulo: Hedra, 2005.

GINZBURG, C. Mitos, emblemas, sinais: morfologia e história. Tradução de Federico Carotti. São Paulo: Companhia das Letras, 2009. 
Nuntius Antiquus, Belo Horizonte, v. 12, n. 1, p. 117-130, 2016

THE GREEK ANTHOLOGY. With an english translation by W. R. Paton, in five volumes; Cambridge: Harvard University Press/ London: William Heinemann, v. I-II and V, 1960; v. III, 1958; v. IV, 1956.

GRIMAL, P. O amor em Roma. Tradução de Hildegard Fernanda Feist. São Paulo: Martins Fontes, 1991.

HESÍODO. Teogonia: a origem dos deuses. Edição bilíngue. Estudo e tradução de Jaa Torrano. São Paulo: Iluminuras, 2007.

HORÁCIO. Odes e epodos. Tradução e nota de Bento Prado de Almeida Ferraz; introdução de Antonio Medina Rodrigues; organização de Anna Lia Amaral de Almeida Prado. São Paulo: Martins Fontes, 2003.

LAPA, M. R. Das origens da poesia lírica em Portugal na Idade Média. Lisboa: Edição do Autor, 1929.

MARTINS, P. Elegia Romana: construção e efeito. São Paulo: Humanitas, 2009.

OVÍDIO. Amores; Medimina faciei femineae; Ars amatoria; Remedia amoris. Edidit brevique adnotatione critica instruxit E. J. Kenney, Scriptorum Classicorum Bibliotheca Oxoniensis, Oxonii e Typographeo Clarendoniano, 1989.

OVÍDIO. Os remédios do amor, Os cosméticos para o rosto da mulher. Tradução, introdução e notas de Antônio da Silveira Mendonça. São Paulo: Nova Alexandria, 1994.

PANOFSKY, E. Significado nas artes visuais. Tradução de Maria Clara F. Kneese e J. Guinsburg. São Paulo: Perspectiva, 2007.

PROPÉRCIO. Elegias de Sexto Propércio. Organização, Introdução, Tradução e Notas de Guilherme Gontijo Flores. Belo Horizonte: Autêntica Editora, 2014.

PROPÉRCIO. Elegies. Edited and translated by G. P. Goold. Cambridge, Mass.: Harvard University Press, 1990.

QUINTILIANO. Institutio oratoria. With an English translation by $\mathrm{H}$. E. Butler, Cambridge, MA: Harvard University Press/ London: William Heinemann, books I-III, 1996; books IV-VI, 1995; books VII-IX, 1996; books X-XII, 1998. 
130 Nuntius Antiquus, Belo Horizonte, v. 12, n. 1, p. 117-130, 2016

VERGÍLIO. Eneida. Tradução e notas de Odorico Mendes; apresentação de Antonio Medina; estabelecimento do texto, notas e glossário Luiz Alberto Machado Cabral. Cotia, SP: Ateliê Editorial; Campinas, SP: Editora da Unicamp, 2005.

VEYNE, P. A elegia erótica romana: o amor, a poesia e o ocidente. Trad. Milton Meira do Nascimento e Maria das Graças de Souza Nascimento. São Paulo: Editora Brasiliense, 1985. 